\title{
INFÂNCIA, PASOLINI E EDWARD GOREY - UM ESTUDO SOBRE ESTILO
}

\author{
CHILDHOOD, PASOLINI AND EDWARD GOREY - AN STUDY ON STYLE
}

Nilton Gonçalves GAMBA JÚNIOR

Pontifícia Universidade Católica do Rio de Janeiro

gambajunior@gmail.com

Resumo: O presente artigo relaciona os estudos de Pier Paolo Pasolini sobre a dimensão social do estilo e a literatura infanto-juvenil. Apresentamos uma tipologia organizada em função de faixa etária, que amplia e contrapõe a visão isolada da fase infantil. Como objeto de análise, utilizamos a obra de Edward Gorey - The Grashlycrumb Tinnies.

Palavras-chave: Infância. Literatura. Ilustração. Estilo. Narrativa.

Abstract: This article relates the studies of Pier Paolo Pasolini on the social dimension of style with the children and youth literature. We present a typology organized according to age groups and that expands and contrasts the isolated view of the child stage. As an object of analysis, we use the work of Edward Gorey - The Grashlycrumb Tinnies.

Keywords: Childhood. Literature. Illustration. Style. Narrative.

\section{Introdução}

Este artigo relaciona os estudos de Pier Paolo Pasolini sobre a dimensão social do estilo e a literatura infanto-juvenil. Embora o livro infanto-juvenil não tenha sido objeto de estudo particular do autor e pareça, de início, inusitada esta relação, seus estudos - que vão da literatura ao cinema e à cultura de massa em geral - podem contribuir para uma proposta de análise desse gênero literário. Para esse diálogo com Pasolini, dentro desse universo temático amplo, o foco é: a naturalização da relação entre as categorias sociais de divisão de faixas etárias e os estilos adotados na produção cultural. Por fim, a obra de Edward Gorey - The Grashlycrumb Tinnies - é um caso exemplar de como aplicar a reflexão estudada.

Temos pesquisado no DHIS (Laboratório de Design de Histórias do Programa de Pós-Graduação em Design da PUC-Rio) o problema do gênero e do estilo na sua 
implicação direta com as concepções sociais de gerações, níveis educacionais ou faixas etárias. Em Empirismo herege (PASOLINI, 1981), Pasolini parte da linguística e segue pela semiologia do cinema para falar de uma semiologia da realidade, em que a análise de estilos em suportes híbridos deve levar em conta as naturezas sociais subjacentes. Na coletânea Os jovens infelizes (PASOLINI, 1990) também fica claro o estudo das gerações como uma perspectiva relevante para se compreender fenômenos sócio-históricos. O autor situa a alternância de geração como um problema particular a partir da Segunda Guerra Mundial.

Para delinear a metodologia deste estudo, é necessário partirmos da determinação da classificação dos períodos de vida que incluem a noção de "infantil" ou "juvenil". Esta divisão tem desdobramentos em diferentes áreas do saber, mas, principalmente, é reafirmada de forma significativa no uso laicizado - que nos interessa sobremaneira aqui. Entenderemos "infância", ou "infantil", como uma classificação que tem sua determinação ligada à especificidade de uma faixa etária, no entanto, para a sua problematização, é fundamental confrontá-la com outras faixas que são, por oposição, parte integrante de seu balizamento: o "neonato", antes da infância e, depois dela, o "jovem", o "adulto" e o "idoso".

Assim como as noções dessas fases, as fronteiras entre elas também vão ser complexas, multidisciplinares e de forte apelo ao senso comum. A noção de "neonato" está mais fortemente determinada na medicina, indicando os 28 primeiros dias de nascimento. Após este período, por vezes, chamam-se de "lactantes" os dois primeiros anos e só é considerado como "infância" a partir do segundo ano. Dentro do período da infância, pode haver inúmeras divisões que vão de relações com: a escola (pré-escola, primeira fase do primeiro grau, ou a própria seriação); as fases de desenvolvimento (como as de Piaget; sensório-motora, simbólica, conceitual e das operações formais); a classificação indicativa de audiência (livre, até dez, doze ou quatorze anos); o desenvolvimento biológico (pueril, pré-adolescente, adolescente), e ainda podem diferenciar as fronteiras entre si com as fases subsequentes.

O Estatuto da Criança e do Adolescente determina que se considere "criança" a faixa até 12 anos de idade incompletos, e "adolescente" aquele entre 12 e 18 anos de idade. A literatura infantil é mais comumente balizada entre 2 e 10 anos, pois já se autodenomina de "juvenil" a focada no público de 10 a 16 anos, o que inclui - 
neste último segmento - a pré-adolescência e a adolescência. Por conta disso, o termo "juvenil" aplicado à literatura vai se distinguir da noção de "juventude" mais ampla e posterior, conforme veremos a seguir.

De acordo com a Proposta de Emenda Constitucional - "PEC da Juventude" aprovada pelo Congresso Nacional em 2010 e com o Estatuto da Juventude sancionado em 2013, considera-se "jovem" no Brasil todo o cidadão que compreende a idade entre 15 e 29 anos de idade - sobrepondo-se, assim, apenas com a idade final da adolescência definida no Estatuto da Infância e da Adolescência.

Segundo o Banco Mundial, o termo "juventude" geralmente refere aqueles que estão entre as idades de 13 a 24 anos, ampliando ainda mais a sobreposição com o termo "adolescente" e se aproximando mais do uso, na literatura, do termo "juvenil" o que é coincidente é que a juventude se inicia na adolescência e inclui o início da maioridade legal.

A vida adulta, em termos de responsabilidade legal, no Brasil pode se iniciar aos 18 anos, mas há variáveis que colocam diferentes marcos etários que variam de 16 a 21 anos. De maneira geral, em conformidade com as definições já mencionadas acima referentes ao Estatuto da Juventude, a vida adulta social marcaria o fim da "juventude" e corresponderia ao final da formação universitária com o ingresso no mercado de trabalho - por isso, a variável entre 24 e 29 anos para estipular o seu início.

O "idoso" ou a "terceira idade" está relacionada ao final da fase adulta e ao fim do ciclo trabalhista oficial com o marco da aposentadoria, que pode se iniciar em diferentes idades, mas tem como faixa média entre 60 e 65 anos - o que envolve também algumas questões legais como uso de passes-livres, relações com pagamentos de taxas ou com o Imposto de Renda. A Política Nacional do Idoso (PNI) - Lei $n^{\circ}$ 8.842, de 4 de janeiro de 1994 - e o Estatuto do Idoso (Lei n 10.741, de $1^{\circ}$ de outubro de 2003) definem como "idoso" pessoas com 60 anos ou mais, sendo que a Organização Mundial da Saúde (OMS) definiu, em 2002, que "idoso" seria aquela pessoa com 60 anos ou mais nos países em desenvolvimento e, em países desenvolvidos, com 65 anos ou mais.

Podemos, em um primeiro momento, já observar que os papéis educacionais e trabalhistas são fundamentais nesta tipologia - ainda que, por vezes, subsidiados 
por argumentações de ordem biomédica, antropológica ou psicológica. Esta divisão nos interessa, aqui, tanto pela força cultural dos sistemas e ritos existentes para a sua preservação quanto pelo caráter limitado de sua convenção. Com determinantes de base cultural, esta classificação gera desvios e subversões que nascem da própria prática de indivíduos inseridos na arbitrariedade do sistema, mas, também, emergem de situações de exclusão, tais como as dos sujeitos de determinadas classes sociais que detêm - em relação ao sistema escolar, às práticas de trabalho, aos direitos ou aos deveres civis - outras convenções dissonantes com as da norma hegemônica.

Por conta de todas essas questões, esta classificação será aqui usada não como uma categorização superficial, inválida e que precise ser anulada. Pelo contrário, será abordada como uma convenção importante de fortes impactos e que não pode ser negligenciada nos estudos da sociedade, dos sujeitos e da cultura, ainda que precise sempre ser relativizada e contextualizada.

Partiremos de uma convenção para falar deste tema - "convenção" - e de como deveria isto ser abordado por conta de sua natureza humana e contextual e, portanto, como produto da linguagem, sendo fundamental desconstruir seu uso naturalizado. É como se houvesse, de fato, um determinante de funções nesta tipologia: crianças nos remetem à falta de autonomia, aprendizado, ludicidade e fantasia; jovens à sexualidade, experimentação e subversão; adultos à produção e provisão da vida dos demais e, finalmente os idosos, a descanso e obsolescência.

Esta tipologia é apreendida de forma ampla pelos sujeitos. Pasolini chega a afirmar que - muito antes do domínio da linguagem verbal, apenas pelas relações com a linguagem material - uma criança é capaz de reconhecer os códigos de seu contexto social. Podemos pensar que uma criança, antes de dominar o verbo, já entenderia que as aspectos materiais diferenciam um quarto de criança de outro de adolescente, como se desenha um adulto ou um jovem em um livro infantil ou, ainda, como diversos "agentes" de seu convívio confirmam ou não estes esquemas apontados nas roupas que usa, papéis e estilos.

Pasolini vai chamar essa transmissão de conhecimento pela materialidade de "pedagogia das coisas" - ou seja, as coisas nos ensinam. Não por outra razão, o grande estudo que versa sobre a construção social da noção de "infância" - $A$ história social da Infância (ARIĖS, 1981) - se apropria de dados materiais tais como 
o brinquedo, a arquitetura, os livros e a indumentária a fim de nos demonstrar as modificações ocorridas no sentido desta classificação. Com a mesma finalidade, porém por outra perspectiva, em sua obra Panorama histórico da literatura infantil e juvenil (COELHO, 1991), Nelly Novaes Coelho vai estudar esta produção material em particular - o livro infanto-juvenil - demonstrando suas relações diretas com a construção social da noção de "infância".

Além dos códigos atrelados às faixas etárias, conforme já introduzimos, Pasolini vai nos lembrar também da relevância da sucessão geracional para a compreensão de mudanças históricas a partir do século XX. Se mudanças estéticas, políticas e tecnológicas definem períodos históricos, no século $X X$ essas sucessões podem acontecer de forma mais abrupta - isto é, entre períodos mais curtos e privilegiando algumas das faixas etárias mencionadas acima.

Pasolini vai descrever o aspecto abrupto como um abismo que não só envolve incomunicabilidade de vivências de fatos históricos, de conhecimentos e de informações, mas também da apreensão de uma cultura material que, para ele, será dificilmente transmissível na sua plenitude. Tendências, tecnologias, moda, obsolescência de mercado ou mesmo câmbios de ideologias são vividos de forma fragmentada, com falhas importantes na memória e na transmissão. Walter Benjamin (BENJAMIN, 1994) chamou essas rupturas de "barbárie", já na primeira metade do século $X X$, e as enxerga atreladas às consequências dos "ismos" ligados aos movimentos modernistas e ao culto à ruptura. Pasolini descreve, décadas depois, essa sucessão de estilos como algo já totalmente apropriado pela cultura de massa e engendrado na lógica do capitalismo de consumo. Assim, modificam-se cortes de cabelos, alturas do cós das calças e as linhas do design de um automóvel mudando de forma radical a atmosfera estética de cada época.

Esta estética inovadora e, ao mesmo tempo, destruidora, retira a legitimidade da anterior e vai ter, nesse cenário do capitalismo de consumo, um público específico prioritário: o jovem. A princípio, será para ele que se destinarão principalmente as inovações geracionais, indicando que tipo de música ouvir, que tipo de roupa usar e que tipo de estética desejar. Por isso, a explicitação desse fato naquele verso da famosa canção de Marcos Valle - Com mais de 30: "Não confie em ninguém com mais de 30 anos" - 30 anos é justo a faixa etária indicada pela 
PEC da Juventude e, por outro lado, no mesmo período histórico dessa canção, é que Pasolini faz suas observações (década de 1960).

As sucessões de "juventudes" indicam trocas de estéticas dominantes. É óbvio que este sistema de atualização material irá, aos poucos, ganhar potência e permear toda a sociedade, mas nem todos com a mesma urgência e prontidão do jovem, funcionando mais como uma espécie de "contaminação". Já no início do século XXI, vamos notar investidas mais sistematizadas para crianças, adultos e idosos do que se pensaria de forma tão clara nas décadas descritas por Pasolini. Voltaremos adiante às implicações deste aspecto cultural na literatura infanto-juvenil.

Outra definição importante é o conceito de "estilo". Pasolini vai opor o estudo do estilo ao estudo do conteúdo narrativo. Assim, na linguagem textual, ele entende ser da dimensão linguística o estudo do estilo e da dimensão narrativa o estudo dos modelos de intriga, e chega a afirmar que as consequências sociais mais relevantes estão no estudo do estilo, e não no da intriga isoladamente, muitas vezes imutável e mais ligada à noção de "gênero". Assim, podemos fazer a mesma correspondência no estudo da ilustração, entendendo "estilo" muito mais como as variações nos elementos da linguagem visual do que nos temas abordados - muito embora Pasolini aponte que o fundamental seria conduzir ambos os estudos juntos, dando ao gênero, ao tema e ao conteúdo o estudo dos enfoques da linguística e da análise da imagem. Com esta relação estabelecida Pasolini vai distinguir, então, o "semantema" do "estilema", lembrando que elementos de significação são distintos dos de diferenciação estética.

Portanto, aqui, podemos nos referir ao livro infanto-juvenil como um gênero literário - e, de uma maneira mais ampla, artístico, para dar conta da forte presença da imagem. E, dentro da abordagem do gênero, podemos perceber diferentes estilos nos textos e nas ilustrações: uma ilustração pode ser, por exemplo, impressionista, étnica ou geometrizada. Como a distinção é naturalmente orgânica e não matemática, poderemos observar estilos que definem gêneros e vice-versa. Por exemplo, estudaremos muito aqui o estilo cute, conforme descrito por Daniel Harris (HARRIS, 2001), encontrado no desenho de personagens em veículos tais como desenho animado, quadrinhos ou livros ilustrados, e que mantenham profunda relação com o gênero infanto-juvenil. 
Cute é a aproximação das proporções de um personagem às de uma criança ou um filhote - maior relação do tamanho da cabeça com o tronco. A dissertação de Pedro Sarmento - A naturalização e a representação visual do gênero infantil: a violência na série "Hora de aventura" (SARMENTO, 2014) - usa a obra de Daniel Harris para aprofundar o estudo do cute no contexto da produção para crianças e vai apontar, bem além da proporção cabeça/corpo, o uso de formas arredondadas, o desfoque, as cores pastéis ou vivas, a referência a materiais indicados para a infância tais como pelúcia e plástico mole que, segundo o autor, irão reforçar a associação da criança com a ideia de um ser que precisa ser cuidado - causa principal das referências estéticas daquilo que é considerado cute.

Apresentados estes primeiros conceitos, podemos partir para a análise de alguns elementos de estilo na literatura infanto-juvenil. $O$ foco deste estudo constitui a análise da imagem, mas se baseia sempre na relação com os textos, principalmente tendo como referência a obra de Pasolini, que utiliza, para os estudos de estilo, a problemática particular da linguística. Ele usa como exemplo a Itália unificada, onde ele aponta a criação de um único idioma arbitrário e artificial diante da diversidade dialetal da região. O autor enxerga, neste fenômeno, um caso exemplar para formular o que chama de uma "categorização geometrizada" de estilos literários.

Esta categorização de Pasolini remete a uma organização geométrica porque defende três áreas com níveis espaciais e, em seguida, promove a identificação de fluxos que desenham linhas de percurso entre elas, começando com a definição de um nível médio, tanto para a língua quanto para a literatura. No âmbito da língua, a primeira definição desta linha média constitui certa artificialidade em relação a alguns níveis sociais, conforme se segue:

\footnotetext{
Se eu tivesse que descrever de modo sintético e vivaz o italiano, diria que se trata de uma língua não, ou imperfeitamente nacional, coberta por um corpo histórico-social fragmentário, quer no sentido vertical (as diacronias, a sua formação por estratos), quer no sentido da extensão (as diversas vicissitudes históricas regionais que produzem várias pequenas línguas virtualmente concordantes, os dialetos, e as diferentes dialetalizações sucessivas do koiné). (PASOLINI, 1981, p. 23).
}

A segunda associação seria a desta língua com uma classe social, a burguesia. Esse recobrimento linguístico de uma realidade fragmentada, que vai ser foco de sua obra, tem relações com a ideia de uma prática média que se sobrepõe e 
se sobrepuja às demais por seu vínculo à ideia de "universalidade". Esta universalidade naturalizada dos valores burgueses vai tornar a língua autorreferente, sem valores de problematização internos.

Para categorizar a literatura dos anos 1950 a 1970 na Itália, Pasolini também vai partir do conceito de uma "literatura média" intimamente implicada com essa natureza linguística. Vai descrever, ainda, que a literatura média pode também ser entendida como a literatura escolástico-acadêmica com características burguesas.

Esta faixa média se delimita acima por uma literatura superior (sem hierarquia de valor) que contempla a literatura chamada de "sublime" e que consegue se relacionar com mais referências históricas e estilísticas, relativizando a posição de autorreferente ou a ideia de universalidade. Porém a descreve, ainda, como hiperlinguística e hermética, porque o distanciamento conseguido em relação à língua média se dá apenas por razões estilísticas e não produz, de fato, críticas ao aspecto que lhe interessa: os riscos da perda da dimensão social da linguagem. Chega a usar a expressão "torre de marfim". Também vai colocar, nesta análise, algumas produções da vanguarda italiana que se ligaram ao fascismo, enxergando, no terror à realidade, desprezo estilístico da figuração e do naturalismo - um mecanismo de defesa que os obstrui em relação à dimensão social da linguagem.

Pasolini, porém, lembra do mérito de que há neles uma batalha linguística, sim, contra a visão monoparadigmática e totalitária da burguesia, há um embate crítico contra sua força centrífuga. No entanto, por outro lado, lembra que o "estar no mundo" dessas práticas é burguês - por isso, acaba também reduzindo a força do ideal de negação do cânone médio. "Seus heróis são burgueses, e seus ambientes são burgueses" (PASOLINI 1981, p. 101), toda a luta é inglória.

$\mathrm{Na}$ linha inferior, nessas décadas, ele identifica a literatura naturalista-veristadialetal que pode se tornar hiperdescritiva e, no afã da mimeses de uma realidade social, se perde na má mimeses platônica, natureza sensível somente, sem reflexão. Pasolini vai associar, a este estilo mais implicado com a diversidade, o discurso direto, que possibilita a mimeses e, por oposição, vai ver, no uso do discurso indireto, a potência de construção da diegeses. Ao se valer desta tensão, analisa um terceiro modelo de enunciação - o discurso indireto livre -, no qual ficam obscuros os limites entre mimeses (mostrar) e diegeses (contar). Nos seus estudos, há uma aprofundada análise da obra de Dante Alighieri, de onde retira exemplos de discurso 
indireto livre e suas indefinições entre o mostrar e o contar, além das mesclas entre os estilos do autor e do personagem. O discurso indireto livre permite uma análise que desenha nuances e vetores que atravessam as fronteiras de suas faixas.

Desenhando aos poucos as linhas de fluxos entre as faixas, vai enxergar autores da linha superior que se apropriam do dialeto e os difundem em estilos médios ou literaturas naturalistas que remetem a uma elaboração sublime. No entanto, ao final, o mais relevante deste primeiro panorama de $O$ empirismo herege é o vetor do domínio universalizante da língua média. Pasolini chega a falar de um cânone médio para mostrar o fenômeno como um fato cultural que se situaria bem além do sistema linguístico apenas.

No início dos anos 1970, Pasolini vai descrever um declínio do interesse pelo estilo do cinema dito "engajado" e conta que sai de moda não só o pensamento marxista mas também, junto com ele, o neorrealismo italiano e qualquer sentido de ideologia. "Contestação do indivíduo que protesta, do anormal, do diferente. Declínio da Ideologia." (PASOLINI, 1981, p. 98). Nesse novo cenário, a obsolescência dos sistemas críticos e reflexivos liberou a burguesia no âmbito linguístico: se, antes, a burguesia aceitava a sua má consciência ainda que sem densidade utópica, agora o declínio do engajamento constitui o declínio da problematicidade que se absorve no hedonismo do capitalismo de consumo. Pasolini vai classificar este contexto como um fenômeno de estilo com base social - uma sociedade, agora, com uma nova faixa média de estilo e de consumo e sem problematização. É desta faixa média que vai sair o delineamento, em certo sentido, tanto da "torre de marfim" quanto da má mimeses, pela força unívoca de um modelo universalizante.

$\mathrm{Na}$ busca da compreensão do funcionamento deste nível médio, Pasolini propõe o termo "nivelamento", que descreve como a saúde obscena do capitalismo, o mais naturalizado e naturalizador dos efeitos. Para conectar esse debate de Pasolini à contemporaneidade, vale a menção ao atual ciclo hipster na moda, tal como um exagero na força unificadora proposta por Pasolini, vista aqui em sucessão de estilos geracionais. 


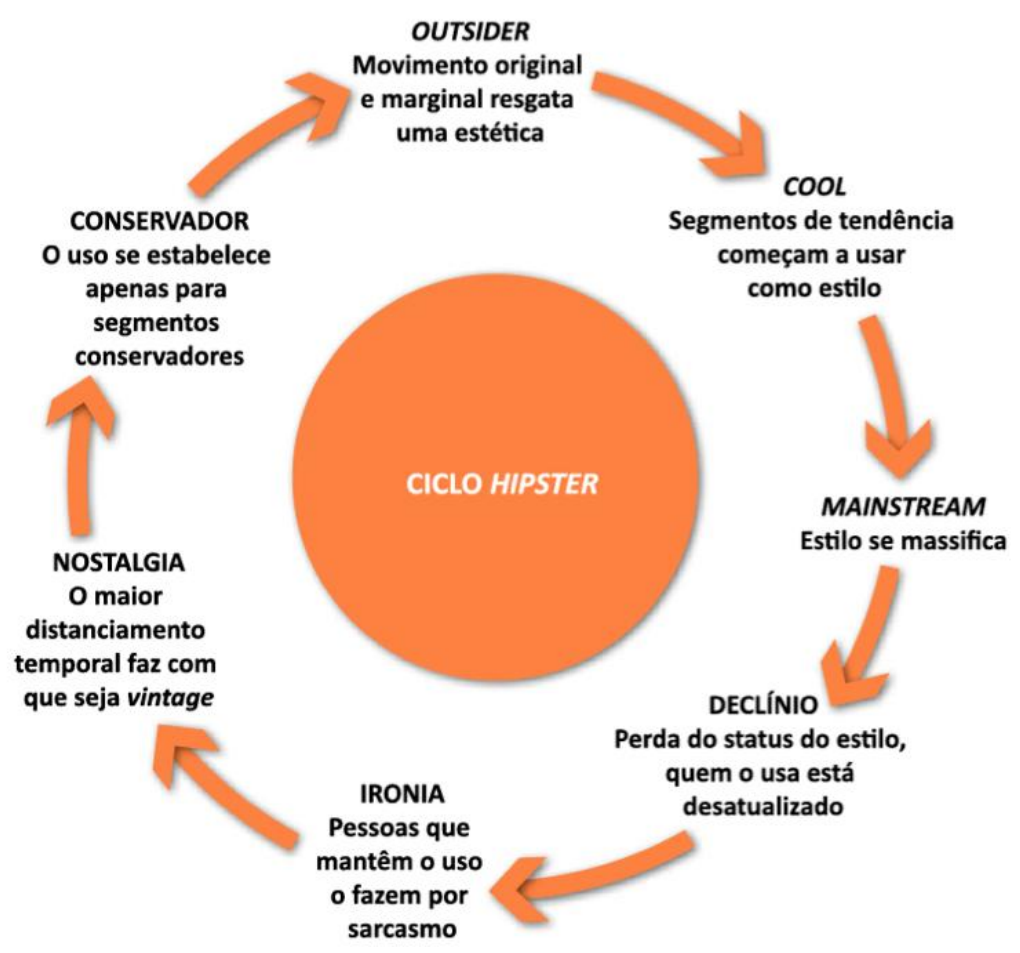

Figura 1: Ciclo hipster

O fluxo proposto por Emily Miethner adiciona não apenas a ideia de sucessão geracional, mas de reutilização e releituras, em um ciclo de apropriação de expressões marginais pelo consumo médio que passa por um momento importante dado pela particularização hermética do cool. Esta passagem ou filtro irá constituir uma etapa fundamental para a legitimação de todo o processo.

Este novo recurso para o nivelamento incorpora, agora, a ideia de uma subversão, ou algum aceno de problematicidade frágil, que seria a escolha "dialetal" temporária no nível outsider. Pasolini, em sua obra, usa o termo "liberdade concedida" como um controle social até das esferas de transgressão. O ciclo hipster denuncia que este nível médio vai saber conviver, cada vez mais, com suas próprias oposições: veremos isso nas fáceis incorporações do marginal pelo status quo, do underground pelo maistream e do cool pelo que é massificado, em um movimento orgânico, em que na própria ruptura já se encontra a semente da incorporação. Funções tanto do hermético sublime quanto do massificado nível médio se unem no cool, que legitima uma passagem, e sem o qual a força libertária do marginal sucumbe à invisibilidade.

Veremos, ainda, que nem sempre a mecânica é simplesmente a apropriação de releitura, já que poderíamos pensar, de forma otimista, que muito do que emerge 
como marginal é realmente inovador - podemos pensar, por exemplo, no Punk e no Hip-Hop não como movimentos de releitura, mas de novos recursos estilísticos. Conforme mencionamos anteriormente, a posição da juventude vai ser estratégica neste sentido. Quem poderá experimentar de forma original, sem comprometer o esquema produtivo, mas já com alguma autonomia para aplicar o novo sistema estético em diferentes níveis de atuação tais como na criação artística, na escolha de mídia, no consumo de vestuário, na cultura e até mesmo na sexualidade?

É óbvio que este grupo interessa exatamente por estar à margem da integração total ao sistema produtivo, muito embora o sistema já a isto se destine, transformando paulatinamente rebeldia em estilo de produtos massificados. A sucessão de estilos passa a ser, na lógica de consumo, quase uma etapa ritualística de despedida de uma faixa subversiva e inovadora ("juventude”) para o compromisso com a conformidade ("adulto"). Na fase adulta, cortam-se os cabelos e mudam-se as roupas, ambos agora serão adequados às várias cartilhas de $\mathrm{RH}$ (Recursos Humanos) que lhe lembrarão de que a transgressão acabou: portanto enquadre-se, não exponha a sexualidade, a diferença ou o exotismo. Se ainda existirem, disfarce!

Ao ocupar essa relevância central, a juventude vai virar um valor médio que atuará tal qual uma "metástase" para as outras fases. Cada vez mais cedo, a criança deseja os ícones e as possibilidades desse grupo, e, cada vez mais, adultos e idosos querem ser "jovens" em algum setor possível, ao menos querem demonstrar que ainda podem sê-los.

A centralidade da cultura jovem já pode ser um item a nos direcionar ao estudar o estilo da fase fronteiriça - a adolescência ou a relacionada ao livro juvenil. É interessante notar como no audiovisual, no teatro ou na literatura, os contos de fada (fantasia) ou os conteúdos explicitamente didáticos vêm perdendo força para o público infanto-juvenil. Referências a estrelas de rock, a modismos de roupa e até a relações afetivas vão sendo incorporadas menos como um indício de transição e muito mais como um sintoma de contaminação pela outra faixa - a da "juventude".

No DHIS trabalhamos muito com teatro infantil e, em um dos projetos de pesquisa, identificamos que, neste segmento, a distinção pode ser ainda mais cruel (GAMBA JR., 2008). Se, no audiovisual, um estilo infantil já pode propor um novo gênero como "família" - que é assim reconhecido por ser assistido por diferentes 
faixas etárias -, no teatro infantil o público vem baixando cada vez a faixa etária, contando apenas com um grupo que ainda não tem a obrigatoriedade de ter que se distinguir da fantasia ou de certos códigos tipicamente infantis por conta da contaminação com o cânone médio do juvenil.

$\mathrm{Na}$ literatura infanto-juvenil, temos uma condição intermediária entre o audiovisual e o teatro. Se, por um lado, ainda não temos o produto "família" em larga escala, há o pressuposto de algum nível existente de compartilhamento dos adultos ou entre adolescentes, e há também mais produtos limítrofes. O pouco compartilhamento verificado no consumo do teatro infantil faz com que se precise cada vez de menos complexidade e de mais certeza da compreensão integral pela criança de forma isolada - mas, por outro lado, sem poder aumentar a faixa etária, resta simplificar os conteúdos, o que acaba criando, por vezes, um estilo de exagerada simplificação formal no texto, na imagem e na linguagem cênica, isto sem citar algumas encenações que rompem com este paradigma.

Além de pensarmos na contaminação com a centralidade crescente do jovem na literatura infanto-juvenil, podemos, por outro lado, refletir também sobre quais outros protagonismos de consumo foram dados à criança pela publicidade, pelos distribuidores e pela própria cultura. Para tanto, basta lembrar a força da polêmica nas discussões sobre a legislação da publicidade para a criança. Mais uma vez, respeita-se o esquema cute de ser cuidada, de não ter autonomia, mas, paradoxalmente, assume-se um vetor de comunicação muito bem-sucedido e não mediado entre o mercado de consumo e a criança, ameaçando o paradigma dessa pretensa falta de autonomia. Aí chegamos a uma nova centralidade, a da própria infância. A tese de Raquel Salgado (SALGADO, 2005) chega a usar o termo "parricídio", tanto no ato de representação, quanto no de consumo, e constitui um ótimo exemplo dessa nova potência autônoma, evidenciada também na facilidade de subversão da mediação dos adultos em sistemas interativos de comunicação tais como os canais de TVs a cabo, a internet e a telefonia móvel ou tablets. Tudo isso corroborando para colocar em cheque a ideia de domínio integral dos cuidados, da mediação, dos filtros, dos conteúdos e das experiências da criança.

Começamos, então, a perceber as falhas típicas dos estilos médios convencionados, naturalizados e sem espaço de autorreflexão. Conforme afirma Pasolini, o cânone médio pode se tornar demasiadamente artificial como um idioma 
que ignora o dialetal. Do mesmo modo, vemos esta visão histórica de infância se debatendo com novas experiências da criança, por exemplo, ao discutir a audiência de temas tabus como a violência, a sexualidade ou mesmo a pornografia. Quase renascendo uma criança ancestral, medieval, que, como descreve Ariès, não era ainda impedida de buscar acesso cultural a esses conteúdos.

Também podemos ver, nesses sistemas, as forças internas de atualização que propõem novos estilos, novos modelos. A literatura infanto-juvenil se consolida como um campo fértil de densa experimentação e problematização artística, por isso há grandes movimentos de autoquestionamento e de implicação com referências externas, construindo o seu fôlego para subversões em algumas direções.

Pasolini, no entanto, lembra que há de se tomar cuidado com a força da ruptura estilística, pois pode gerar um rebote. "O escândalo linguístico desempenha o mesmo papel do escândalo moral. Ambos, quando levados ao extremo, dão lugar a uma nostalgia." (PASOLINI, 1981, P. 131). Ele a descreve como a nostalgia do código, uma volta reacionária ao cânone. "Quando a mensagem excede certos limites de transgressão do código, faz nascer, automaticamente, a nostalgia do Código." (PASOLINI, 1981, P. 131). Fazendo novamente uma crítica à vanguarda italiana, afirma que infrações mecânicas e programadas se esgotaram, embora sejam infinitas como combinações matemáticas. Infrações do código sem dimensão social têm agressividade reduzida, se tornam um novo modelo de tradição.

Sintetizando, temos uma centralidade do estilo e do conteúdo jovem sobre outros conteúdos, uma centralidade das convenções dos papéis estabelecidos do adulto diante da criança, uma centralidade da criança na relação com o mercado cultural, pouco reconhecida e complexa e, por último, uma centralidade do cânone médio que há em qualquer gênero e que também há, evidentemente, na literatura infanto-juvenil.

Para podermos desenvolver toda essa reflexão aplicada agora a um objeto concreto, trazemos aqui uma obra de Edward Gorey, autor e ilustrador da segunda metade do século XX que tinha como particularidade o tom macabro do texto e das ilustrações, que contrastavam com o estilo hegemônico voltado para crianças. Gorey influenciou artistas como Tim Burton, Lemony Snicket e Shaun Tan. O livro escolhido é o abecedário The Grashlycrumb Tinies, publicado em 1963, em que o 
autor ilustra, para cada letra, um nome de uma criança que vive uma passagem trágica e, ainda, uma frase que também a descreve com conteúdo mórbido.

A tradução do título é complexa, pois parece conter um neologismo que inclui um radical de origem dialetal e uma gíria. Grashly + Crumb + Tinies seria associar algo que é nojento com fragmentos - que também podem ser migalhas - e com a noção de "pequeno", no sentido de nomear crianças. Porém, alguns tradutores lembram que crumb pode ser traduzido do inglês americano como "pessoa sem valor". É interessante que Grashlycrumb remete, também, às junções de vocábulos típicas da língua alemã como o nome do clássico Struwwelpeter de Heinrich Hoffman de $1845^{1}$, marco da literatura infanto-juvenil, com mensagens morais de repreensão. Embora essa obra se torne anacrônica tanto quanto ao estilo quanto ao conteúdo, por ser considerado, na atualidade, inadequadamente mórbido para crianças, ela se constitui como referência forte na obra de Edward Gorey, não apenas pelo estranhamento resultante da anacronia do conteúdo como também pelo que era produzido pelo fato de usar um estilo vitoriano das ilustrações.

A intenção do livro é clara: associar o estilo de memorização de letras, tão comum ao aprendizado infantil, a cenas de morte de crianças, o que já é indicado na capa. A capa traz as várias crianças narradas no livro acompanhadas por uma figura soturna, com rosto de caveira e roupa de agente funerário oitocentista. Na quarta capa, a imagem é de um grupo de lápides, já sem o "papa-defunto"."

Na primeira letra, já vemos o tom do livro: $A$ is for Amy who fell down the stairs ("A para Amy que caiu das escadas"). Embora algumas ilustrações deixem margem para uma possibilidade de salvamento, como a queda da escada, outras apontam cenários mais graves, como a da letra $\mathrm{K}: K$ is for Kate who was struck with an axe ("K de Kate que foi golpeada por um machado") ${ }^{3}$, que acaba sendo a primeira página mais trágica, onde há apresentação de sangue e das consequências finais em si. . Como se o autor nos preparasse aos poucos, ou, quem sabe, a escondesse da censura dos adultos que autorizam a compra folheando as primeiras páginas.

A obra de Gorey é sempre classificada como livro infanto-juvenil e, por vezes, apenas como livro infantil mesmo. É óbvio que a obra de Gorey é rica pelo que

\footnotetext{
${ }^{1}$ https://germanstories.vcu.edu/struwwel/daumen_e.html

2 http://brickbatbooks.blogspot.com.br/2013/05/

${ }^{3}$ http://buffleheadcabin.com/post/165339375537/edward-gorey-k-is-for-kate-who-was-struck-with
} 
articula de conteúdos, temas e estilo. O estilo vitoriano das ilustrações provoca nosso tempo a pensar o quanto ainda nos debatemos com noções de infância deste período. As migalhas que aparecem no título falam de uma ideia de infância que, além de não ser um ser completo - por ser considerado apenas parte de um indivíduo -, também é uma parte não tão significativa. As migalhas também lembram uma visão de infância que envolve a ideia de algo arisco, difícil de cuidar, manipular e limpar. O "deixar limpo" que as migalhas evocam estão lá nesta noção de "infância", que inclui enquadrar nos sistemas civilizatórios. O que Gorey faz, ao remeter a este estilo anacrônico, é um estranhamento vintage, com um funcionamento similar, não idêntico, a fase cool do ciclo hipster. Tanto que, em diversas pesquisas efetuadas sobre Gorey, vemos que sua obra se tornou cult (termo similar para o cool, com um pouco mais de permanência), inclusive para jovens e adultos.

Mas o interessante é que Gorey recupera um estilo hegemônico, um código médio e facilmente reconhecível e identificável com a literatura infanto-juvenil do século XIX. Ao retomar este estilo, já desprestigiado nos anos 1960, Gorey também nos provoca com temas e conteúdos que deveriam ter ficado no século XIX, segundo o novo estilo médio. A severidade educacional e a ideia de punição física e mórbida não combinam mais com as necessidades do cute. $\mathrm{O}$ cute quer imagens sem ferimentos e que não representem riscos. As formas arredondadas e os materiais plásticos não ferem, não machucam e, neles, não se mimetiza este tipo de perigo. Harris vai, inclusive, mencionar certa perversão desses brinquedos ou desta representação que induz que é permitido morder, apertar e jogar sem destruir. Porém, Gorey nos faz pensar: que risco, que lesão e que consequências foram essas que foram minimizadas? Acaso modificam algum paradigma claro de comportamento social quanto à criança?

$\mathrm{Na}$ verdade, o novo estilo médio da literatura infanto-juvenil oblitera qualquer tema e estilo que suscite a violência. A pesquisa de Pedro Sarmento (SARMENTO, 2014) nos mostra como, na classificação indicativa de audiência para programas infantis, a violência, junto com o sexo, é o principal critério de avaliação. No entanto, o estigma da criança vista como alguém a ser protegido dessa violência só aumentou e se complexificou em relação à produção vitoriana pois, além da preocupação do adulto com o acontecimento perigoso e a visão da criança como um 
ser mais frágil e despreparado, adicionou-se, na contemporaneidade, a não representação desses riscos. A morbidez é interdita, assim como a violência explícita ou a sexualidade. Sempre lembrando, aqui, que estamos falando de um estilo médio.

Gorey, com seu livro, nos faz ver como a crítica ao século XIX não é apenas estilística à natureza burguesa e média da criança muda. Embora continue tendo uma relação com o risco de violência que a pode punir, por outro lado agora não pode ter mais clareza deste constructo. A criança não pode mais ver golpes de machado ou de tesouras que nos punam pela falta de atenção, tal como acontecia em Struwwelpeter. E, com nossos olhos focados apenas na dimensão estilística cute de não ver o mórbido, assim acentuamos ainda mais o que não foi ainda eficazmente problematizado: a visão da infância como "migalha".

O caráter didatizante também é ironizado ao se construir um abecedário e ao usar as frases curtas como um estilo linguístico correto à simplicidade de compreensão do texto por parte da criança. O uso de adjetivos tais como "afogado" ou "golpeado", além da utilização de personagens como ladrões e caveiras, mesclam no estilo aquilo que seria inadequado.

O estilo vitoriano da ilustração - embora não ceda integralmente ao cute por conta de ser de um período anterior ao uso massificado desta estratégia - tem algumas pequenas alterações formais de representação que são interessantes de serem observadas: por exemplo, a redução do nível de realismo comparada à ilustração de Struwwelpeter. Ainda podem ser observadas, na obra de Edward Gorey, uma simplificação formal e uma redução de escala dos traços fisionômicos.

Os olhos, bocas e narizes de Gorey são pequenos pontos no limite da visibilidade, que levam quase a uma neutralidade expressiva, desencadeando certa apatia. Em Struwwelpeter, há uma delicadeza de traço na representação do rosto infantil, no entanto isto só não é detalhado quando há uma impossibilidade de escala. Mas quando é possível, por vezes há expressões de horror ou sofrimento. É óbvio que Gorey toma partido da questão da escala, por conta do formato diminuto do livro e da maneira como faz as composições, em que a criança venha a ocupar uma área muito pequena da ilustração podendo, assim, minimizar ainda mais a 
expressão fisionômica. Na ilustração para a letra $\mathrm{N}^{4}$, a representação do rosto de um personagem escondido por uma janela ocupa uma diminuta semiesfera no canto da página. Uma das poucas exceções constitui, novamente, a de Kate da letra K, por conta do exagero do sangramento ou afundamento dos olhos.

Sobre o resultado final desta estratégia estilística de fidelidade e amenização de algumas características da ilustração vitoriana, podemos pensar em três aspectos: 1) certo ar fantasmagórico, de "quase-mortos"; 2) uma redução da dimensão expressiva de terror, dor ou sofrimento; 3) uma acentuação das formas caricaturais adequadas ao gênero infanto-juvenil no século XX.

O primeiro aspecto parece apontar para uma referência a várias construções típicas do audiovisual e de representações mais remotas do próprio teatro. Por conta da dimensão mimética de ambos (artes cênicas e cinema), o "morto-vivo" ou o "quase-sem-vida" é representado pela apatia fisionômica e pela descoloração da pele, típicas de cadáveres. Tanto é assim que as expressões das crianças colaboram para um clima de terror: se elas não sofrem como as crianças vitorianas de Struwwelpeter, elas também não reagem e tampouco se encantam, mostrando sempre apatia de quase cadáveres.

O segundo aspecto, intimamente ligado ao primeiro, nos faz pensar na classificação indicativa brasileira, por exemplo, na qual sofrimento e consequências emocionais da violência aumentam em muito a faixa etária recomendada. No entanto, esta apatia que pode remeter a outro aspecto mórbido - a ausência de vida ou de reações - não possui uma categoria explícita na nossa classificação indicativa e, de certa forma, nem sequer há essa clareza no senso comum que, de alguma forma, a classificação expressa. Assim, Gorey consegue mais uma vez driblar não somente a operacionalidade de alguma recomendação institucionalizada mas, ainda, certo senso comum do consumo.

E, por último, a aproximação de uma representação estilizada que é vinculada não só ao estilo cute mas, também, a uma estética altamente recomendável para crianças como cânone médio, faz com que toda a ousadia de Gorey não se configure em um escândalo completo, impeditivo de sua eventual aceitação.

${ }^{4}$ http://www.guibingzhuche.com/WDF-1394394.html 
A obra de Gorey pode suscitar, ainda, muito mais material de análise formal e de apontamentos sobre nossos enquadramentos estilísticos e sociais da infância e da classe média. Um estudo interessante seria a proporção de seu consumo por jovens e adultos que, devido às rupturas conseguidas pelo autor, permitem-se ler um abecedário de frases curtas e ainda ilustrado em formato típico para crianças. É interessante entender que aspectos do tema, do conteúdo e do estilo vão fazer esta passagem de The Grashlycrumb Tinnies para cool em outras faixas etárias. Há anos pergunto quem dentre os meus alunos de Design conhece esta obra: a quantidade que responde afirmativamente se torna crescente, quase sempre me explicando que a aproximação com esta obra se deu na juventude ou já na universidade. Óbvio que, no Brasil, muito desta situação se justifica também por conta de ainda estar em língua inglesa. Porém, é claro que The Grashlycrumb Tinnies provoca reações e comportamentos inusitados pelo seu nível intrínseco de inovação.

No resto do mundo, também podemos ver uma aceitação crescente decorrente da repercussão, na mídia de massa, de estilos próximos e difundidos pelos seus seguidores, como Tim Burton por exemplo. Sempre lembrando que Pasolini talvez distinguisse Burton de Gorey, não apenas pela cronologia, mas também pela diferença quanto ao nível de contaminação pelo cânone médio e pela potência de escândalo de cada um dos autores - muito mais perto da problematização explícita e provocadora em Gorey. Contudo, um estudo certamente interessante seria entender os diferenciais estilísticos e sociais das obras macabras que vão das origens, como na era vitoriana, ao resgate de Gorey e até a apropriação de Burton. Além disso, compreender seu tempo de permanência - que a mantém na mídia de massa por gerações e gerações, ostensivamente desafiando o ciclo hipster, talvez por simular sempre uma não aceitação. Mas, isto já seria outro estudo diferente.

\section{Referências bibliográficas}

ARIÈS, P. História social da infância. Rio de Janeiro: LTC, 1981.

BENJAMIN, W. Magia e técnica, arte e política: ensaios sobre literatura e história da cultura. São Paulo: Editora Brasiliense, 1994.

COELHO, N. N. Panorama histórico da literatura infantil e juvenil. Rio de Janeiro: Editora Ática, 1991. 
GAMBA JR., N. G. O Adulto e o Infantil em Êta, Seu Bonequeiro! In: "Infâncias possíveis, mundos reais", BRAGA, 2008. 1ํ Congresso Internacional em Estudos da Criança: infâncias possíveis, mundos reais, 2008. v. 2.

HARRIS, D. Cute, quaint, hungry and romantic: the aesthetics of consumerism. Cambridge, Massachusetts: Da Capo Press, 2001.

PASOLINI, P.P. Empirismo herege. Lisboa: Editora Assírio e Alvim, 1981.

Brasiliense, 1990. Os jovens infelizes. Antologia dos ensaios corsários. São Paulo:

SALGADO, R. G. Ser criança e herói no jogo da vida: a infância contemporânea, o brincar e os desenhos animados. 2005. 245 f. Tese (Doutoramento em Psicologia) - Pontifícia Universidade Católica do Rio de Janeiro (PUC-Rio), Departamento de Psicologia, Rio de Janeiro, 2005.

SARMENTO, P. F. A naturalização e a representação visual do gênero infantil: a violência na série Hora de aventura. 2014. 215 f. Dissertação de Mestrado em Design - Pontifícia Universidade Católica do Rio de Janeiro (PUC-Rio), Departamento de Design, Rio de Janeiro, 2014. 